Supplementary Material

\title{
Modulation of Spacing and Magnetic Properties of Iron Oxide Nanoparticles through Polymer-Mediated 'Bricks and Mortar' Self-Assembly
}

Andrew K. Boal, Benjamin L. Frankamp, Oktay Uzun, Mark T. Touminen, and Vincent M. Rotello* 


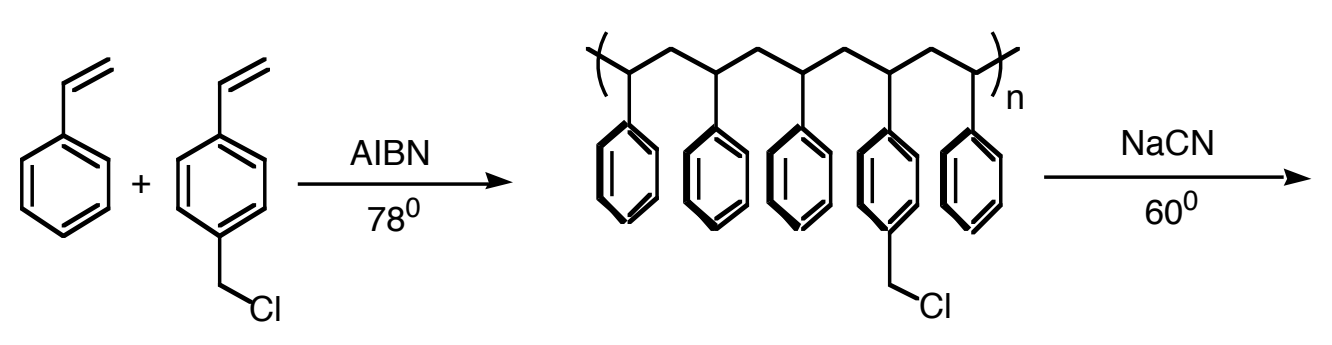

polymer 2; MW = 14400

polymer 3; MW = 21400

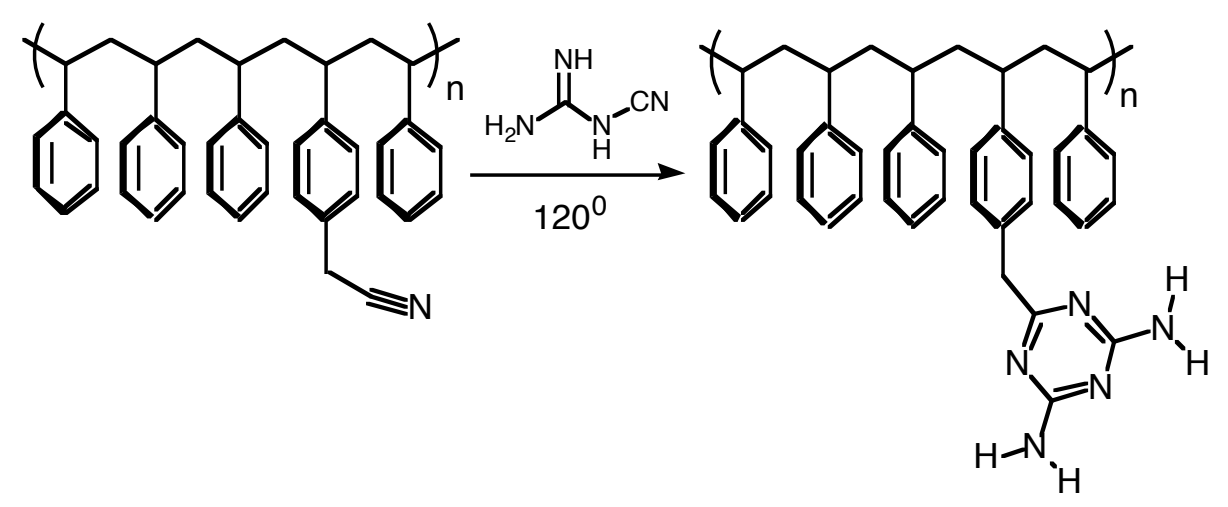

Scheme S1. Preparation of polymers .

\section{General Procedure for the preparation of poly(styrene-co-chloromethylstyrene)}

(Polymers 2-3).

Materials and General Methods All chemicals were reagent grade, and were used without further purification. GPC (Gel permeation chromatography) was performed on a PLgel mixed-Ecolumn ( $3 \mathrm{~m}, 7.5$ x $300 \mathrm{~mm}$, Polymer Laboratories Ltd.), using polystyrene as standard, flow rate $1 \mathrm{~mL} / \mathrm{min}$, with detection at $254 \mathrm{~nm}$. 
Poly(styrene-p-(chloromethyl) styrene), PS-co-CH2 Cl (2) AIBN (0.1 g, 0.60 mmol), PS-co-CH2 Cl (3) AIBN (0.05 g, $0.30 \mathrm{mmol})$ was added to a solution (2) styrene (1.52 g, $14.6 \mathrm{mmol})$ and $\mathrm{p}$-(chloromethyl) styrene (0.55 g, $3.6 \mathrm{mmol}),(3)$ styrene $(1.27 \mathrm{~g}, 12.2$ $\mathrm{mmol})$ and p-(chloromethyl) styrene $(0.46 \mathrm{~g}, 3.0 \mathrm{mmol})$. The reaction mixture was heated at $78{ }^{\circ} \mathrm{C}$ for $20 \mathrm{~h}$, followed by cooling to room temperature. The reaction mixture was then added to methanol $(100 \mathrm{~mL})$; vigorous mixing resulted in precipitation of a white solid, (2) (2.12 g, 75\%), (3) (1.33 g, 77\%) which was collected by filtration, and washed with methanol. The product was dried in vacuo. GPC: PS-co- $\mathbf{C H} \mathbf{2} \mathbf{C l}$ (2) $\mathbf{M n}=14400$, $\mathrm{PDI}=2.8 ;(\mathbf{3}) \mathrm{Mn}=21300, \mathrm{PDI}=2.5$

Poly(styrene-p-(cyanomethyl)-styrene, co-PS- $\mathrm{CH}_{2} \mathbf{C ~ N}$. A solution of (2) (0.5g, 0.035mmol), (3) (0.5 g, 0.325mmol), sodium cyanide (0.100 g, $2.0 \mathrm{mmol})$, and DMF (2 $\mathrm{mL}$ ) was heated at $70{ }^{\circ} \mathrm{C}$ for $48 \mathrm{~h}$ under argon. The resulting heterogeneous mixture was filtered and the filtrate concentrated under reduced pressure. The concentrated solution was precipitated into water. The cream-colored solid product co- $\mathrm{PS}-\mathrm{CH}_{2} \mathrm{CN}(0.41 \mathrm{~g}$, $82 \%$ ) was collected by filtration, washed with water and $\mathrm{CH}_{2} \mathrm{Cl}_{2}$, and dried in vacuo.

Poly(styrene-p-(methyldiaminotriazine)-styrene, co-PS- $\mathrm{CH}_{2} \mathrm{C}_{3} \mathbf{N}_{5} \mathbf{H}_{4}$. A solution of coPS- $\mathrm{CH}_{2} \mathrm{CN}(0.41 \mathrm{~g}, 0.12 \mathrm{mmol})$, dicyandiamide $(0.131 \mathrm{~g}, 1.55 \mathrm{mmol})$, and $\mathrm{KOH}(0.020$ $\mathrm{g}, 0.35 \mathrm{mmol})$ in 1-propanol $(3 \mathrm{~mL})$ was refluxed for $20 \mathrm{~h}$. A precipitate formed as the reaction proceeded. After evaporating 1-propanol under reduced pressure, the resulting crude product was stirred in boiling water for $30 \mathrm{~min}$. The solution was cooled to room temperature and then filtered to collect a cream-colored solid $(0.42 \mathrm{~g}, 86 \%)$. 


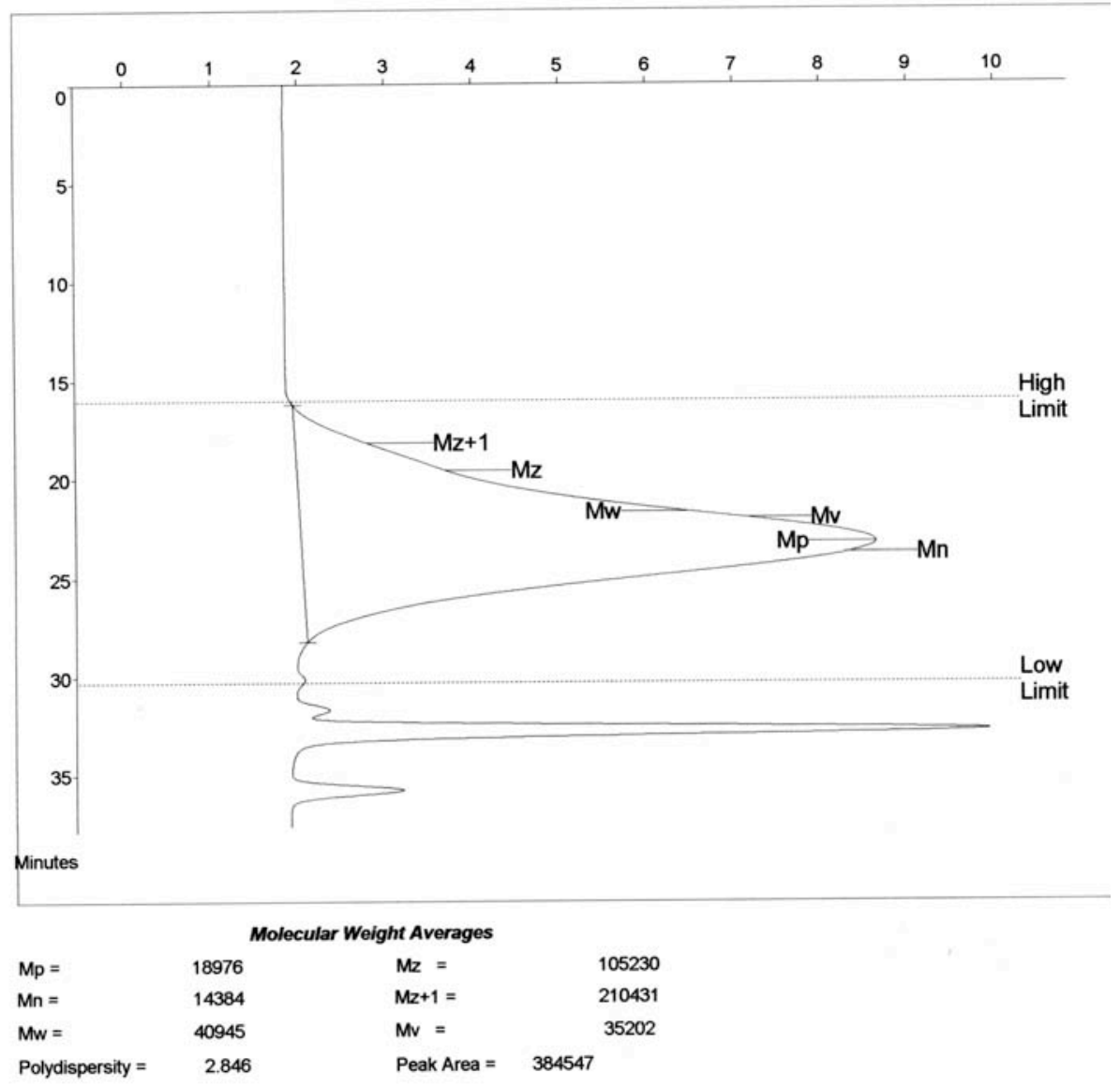

Figure S1. Polymer PS-co- $\mathrm{CH}_{2} \mathrm{Cl}$ (2) GPC trace 


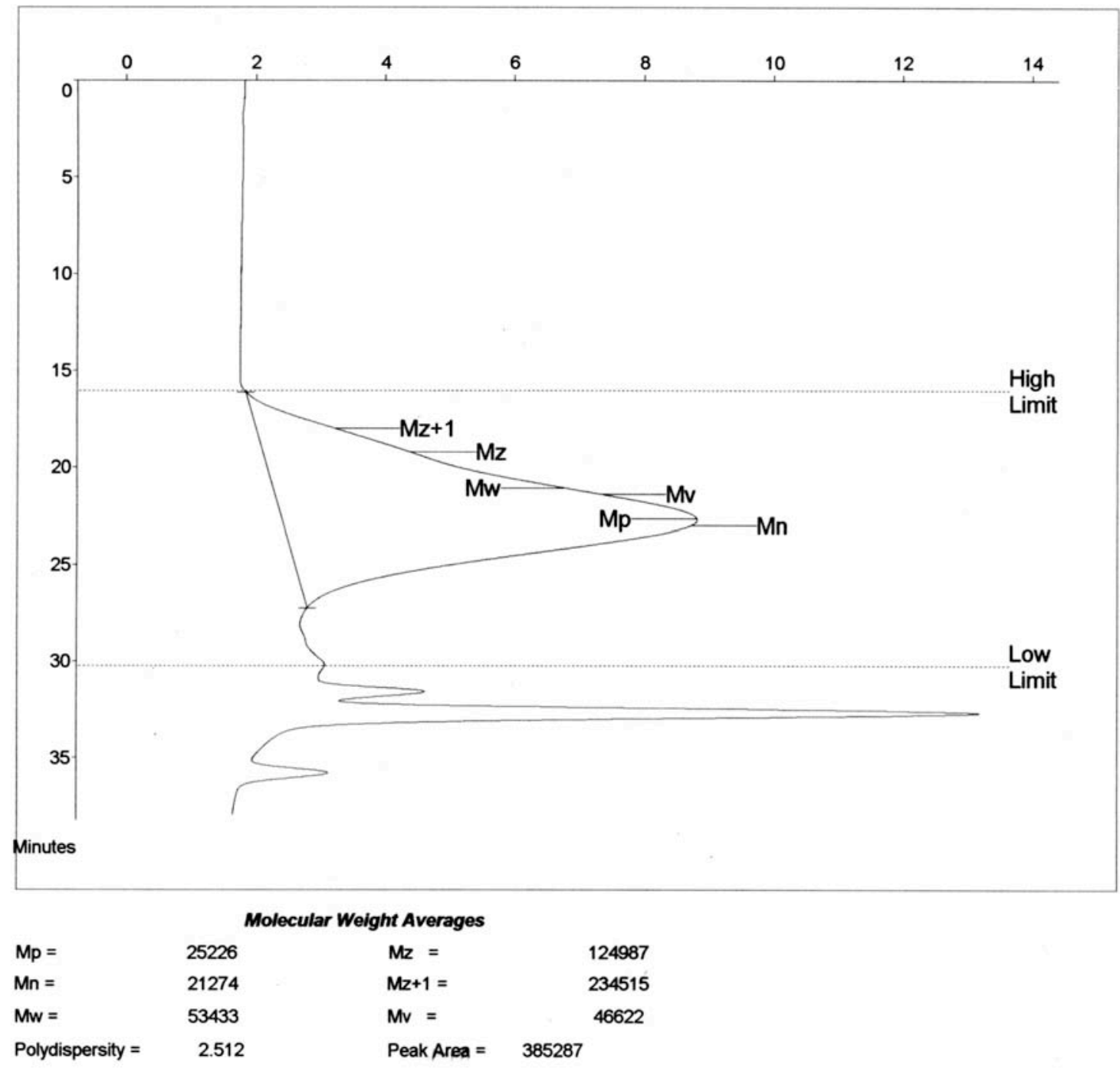

Figure S2. Polymer co-PS- $\mathbf{C H}_{2} \mathbf{C}_{3} \mathbf{N}_{5} \mathbf{H}_{4}$ GPC trace 


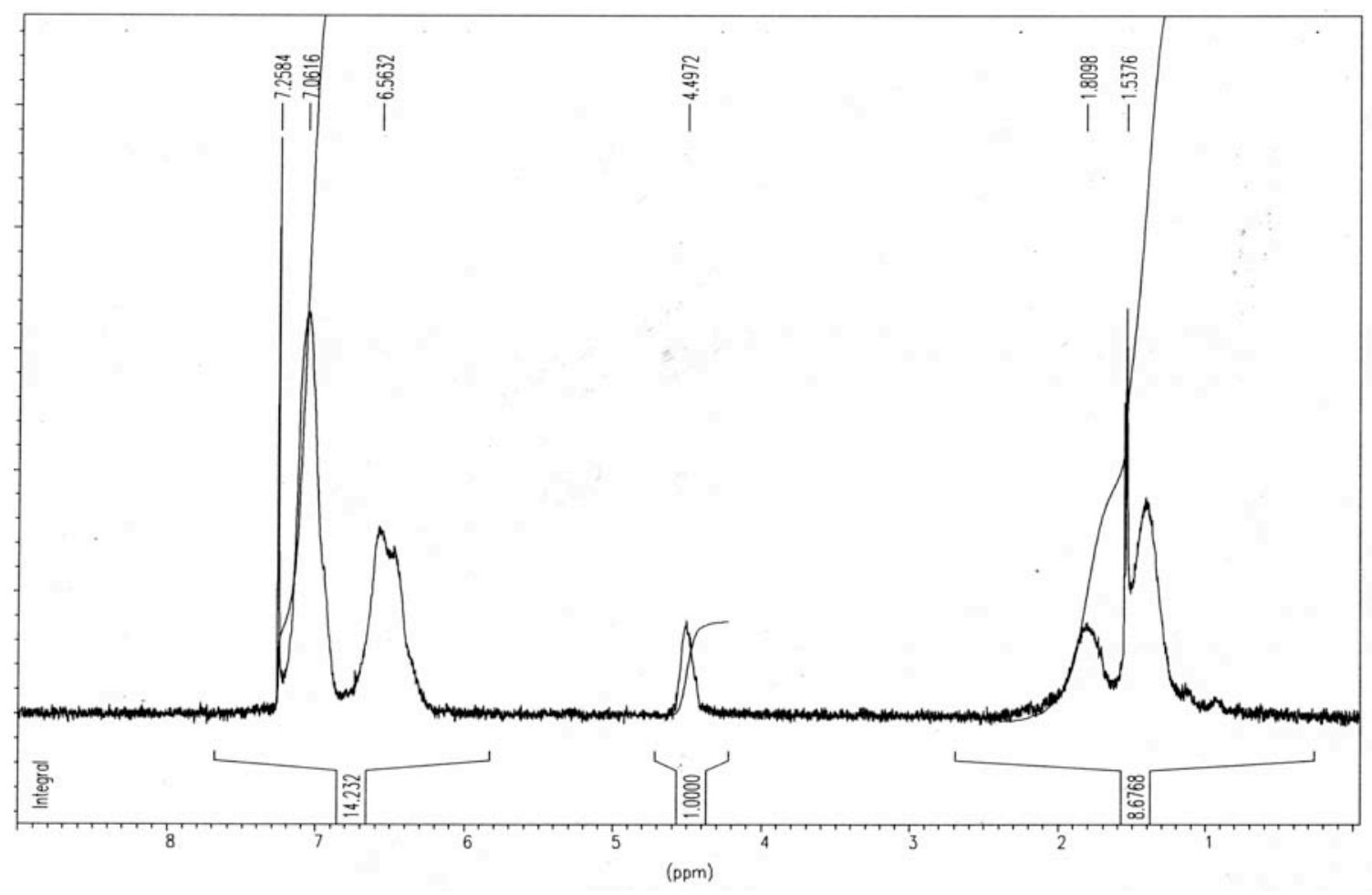

Figure S3. NMR spectra PS-co- $\mathrm{CH}_{2} \mathrm{Cl}$ (2) 


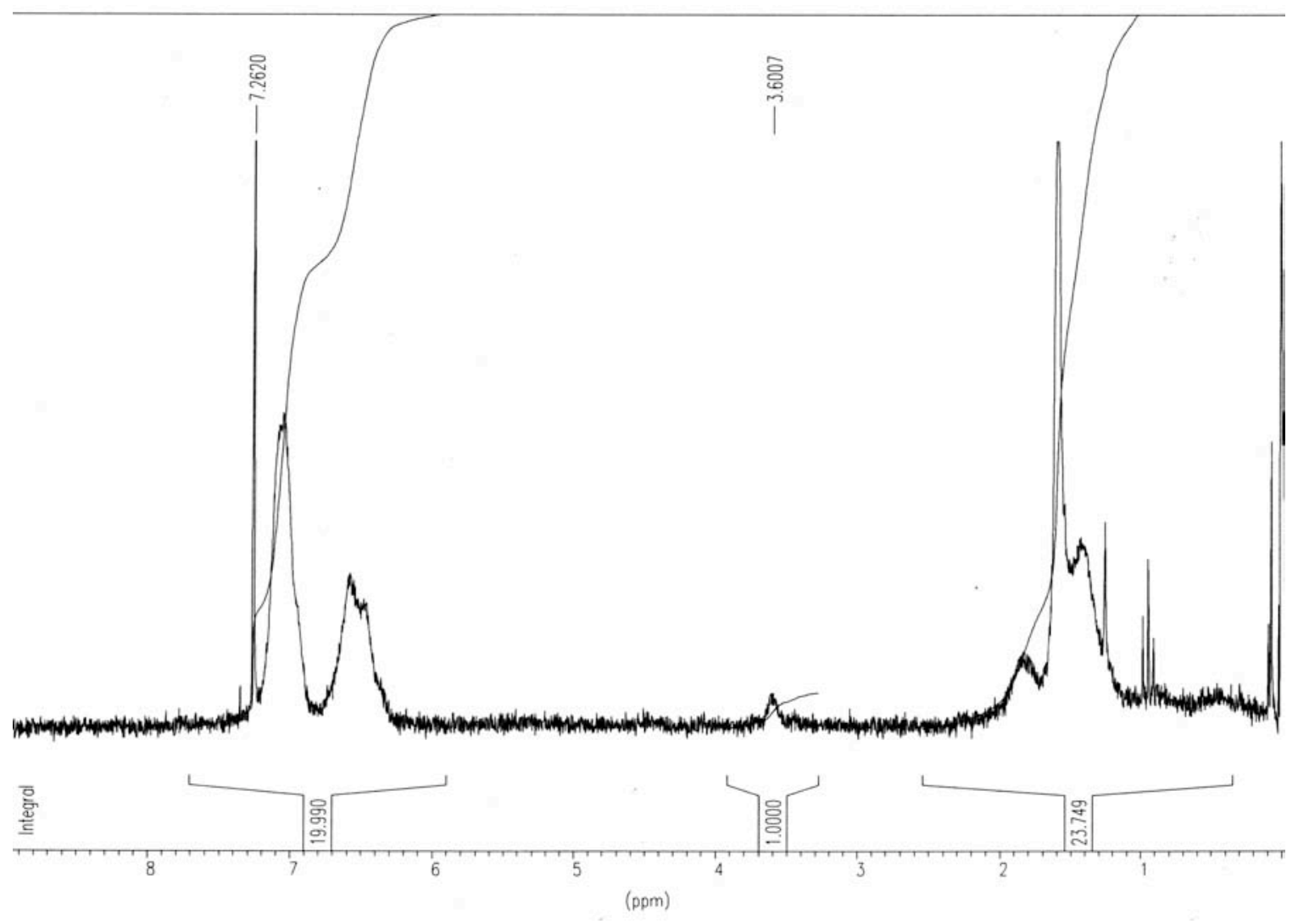

Figure S4. NMR spectra of co-PS- $\mathrm{CH}_{2} \mathbf{C}_{3} \mathbf{N}_{5} \mathbf{H}_{4}$ 

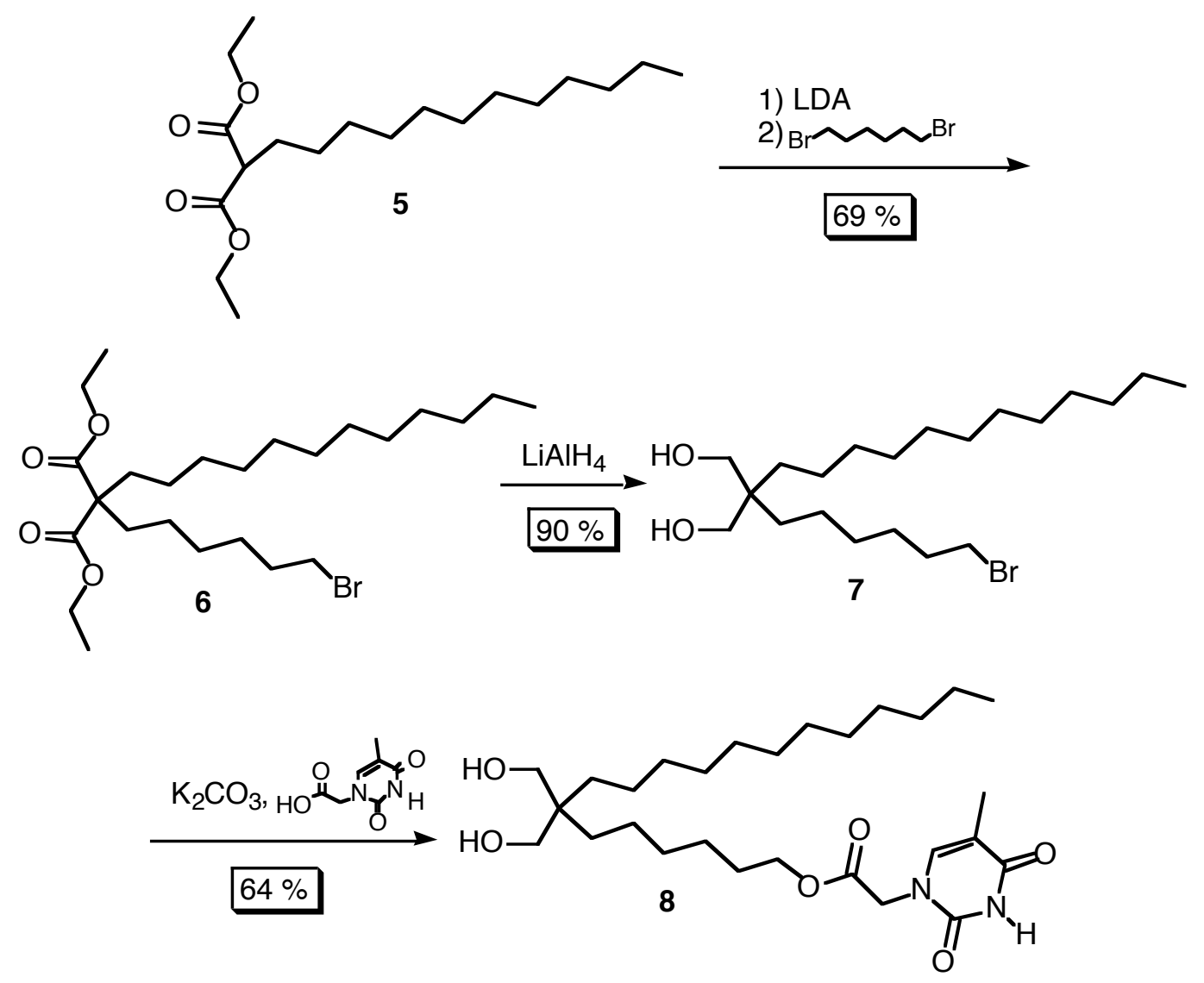

Scheme S2. Preparation of Lignad 8.

Ligand Synthesis. Diethyl 6-bromohexyl-dodecylmalonate (6). In a 3-neck, $250 \mathrm{~mL}$ round bottom flask, diethyl dodecylmalonate $(\mathbf{5})^{\text {Error! Bookmark not defined. }}(5.0 \mathrm{~g}, 15 \mathrm{mmol})$ was dissolved in $100 \mathrm{~mL}$ THF and cooled to $-78^{\circ} \mathrm{C}$. Lithium di-iso-propyl amide $(10 \mathrm{~mL}$ of a 1.5 $\mathrm{M}$ solution in THF, $15 \mathrm{mmol}$ ) was then added drop wise and the reaction warmed to room temperature. After 15 minutes, 1,6-dibromohexane (18.3 g, $75 \mathrm{mmol}, 12 \mathrm{~mL})$ was added, and the reaction refluxed for 48 hours, during which time the solution became black. The reaction was then cooled to room temperature, and carefully quenched with water, changing the solution color to red. The reaction mixture was transferred to a separatory funnel, washed once with a saturated aqueous $\mathrm{NaCl}$ solution, and dried over $\mathrm{MgSO}_{4}$. Solvent removal gave the crude product as a thick yellow oil that was 
chromatographed $\left(\mathrm{SiO}_{2}\right.$; gradient elution: hexanes to 5\% EtOAc: hexanes) to give the product as a light yellow oil $(5.1 \mathrm{~g}, 69 \%$ yield $) .{ }^{1} \mathrm{H} \mathrm{NMR}\left(\mathrm{CDCl}_{3}, 200 \mathrm{MHz}\right) \mathrm{d}(\mathrm{ppm})$ $4.17(\mathrm{q}, 4 \mathrm{H}, J=6.9 \mathrm{~Hz}), 3.39(\mathrm{t}, 2 \mathrm{H}, J=6.88 \mathrm{~Hz}), 1.84(\mathrm{~m}, 6 \mathrm{H}), 1.25(\mathrm{~m}, 34 \mathrm{H}) .0 .88(\mathrm{bt}$, $3 \mathrm{H})$. IR (thin film from $\mathrm{CH}_{2} \mathrm{Cl}_{2}$ on $\mathrm{NaCl}$ plate) $\square \max 2910,2850,1660,1450,1200 \mathrm{~cm}^{-}$ 1. FAB-MS: (m/z) 491.2 (parent ion calc. 491.6), 417, 371, 172.

1-bromo-7,7-bishydroxymethyl-nonadecane (7). In a $250 \mathrm{~mL}$ round bottom flask, 6 $(1.5 \mathrm{~g}, 3.0 \mathrm{mmol})$ was dissolved in $50 \mathrm{~mL} \mathrm{Et}_{2} \mathrm{O}$ and cooled to $-78^{\circ} \mathrm{C} . \mathrm{LiAlH}_{4}(20 \mathrm{~mL}$ of a 1.5 $\mathrm{M} \mathrm{Et}_{2} \mathrm{O}$ solution, $30 \mathrm{mmol}$ ) was added drop wise and the reaction stirred for 15 minuets. The reaction was then quenched at $-78^{\circ} \mathrm{C}$ by the careful addition of water, which produced a thick colorless solution. The reaction mixture was transferred to a separatory funnel, washed twice with $1 \mathrm{M}$ aqueous $\mathrm{NaOH}$, once with a saturated aqueous $\mathrm{NaCl}$ solution, and dried over $\mathrm{MgSO}_{4}$. Solvent removal gave the crude product as a thick yellow oil which was found to be contaminated with some incompletely reacted product. ${ }^{1}$ This material was then dissolved in $100 \mathrm{~mL} \mathrm{EtOH}$, and $\mathrm{NaBH}_{4}(1.0 \mathrm{~g}, 6.0 \mathrm{mmol})$ was then added, and the reaction stirred for 1 hour. The EtOH was then removed, and the resulting white solid was transferred to a separatory funnel with water and EtOAc. The organic layer was washed once with $1 \mathrm{M}$ aqueous $\mathrm{NaOH}$, once with a saturated aqueous $\mathrm{NaCl}$ solution, and dried over $\mathrm{MgSO}_{4}$. Solvent removal gave the crude product as a thick yellow oil which was chromatographed $\left(\mathrm{SiO}_{2}\right.$; gradient elution, EtOAc to $10 \%$ $\mathrm{MeOH}:$ EtOAc) to give the product as viscous, colorless oil (1.08 g, $90 \%$ yield $).{ }^{1} \mathrm{H}$ NMR (CDCl3, $200 \mathrm{MHz}) \mathrm{d}(\mathrm{ppm}) 3.57$ (bs, 4H), 3.41 (bt, 2H), 2.07 (bm, 2H), 1.86 (bm, 2H), 1.26 (bs, 32H), 0.88 (bt, 3H). IR (thin film from $\mathrm{CH}_{2} \mathrm{Cl}_{2}$ on $\mathrm{NaCl}$ plate) $\square \max 3360$, $2910,2850,1490,1050 \mathrm{~cm}^{-1}$. 
1-thyamine acetate-7,7-bishydroxymethyl-nonadecane $(\mathbf{8})$. In a $100 \mathrm{~mL}$ round bottom flask, thymine acetic acid $(1.65 \mathrm{~g}, 8.9 \mathrm{mmol})$ and $\mathrm{K}_{2} \mathrm{CO}_{3}(1.1 \mathrm{~g}, 8.0 \mathrm{mmol})$ were dissolved in $25 \mathrm{~mL}$ DMSO and heated to $60^{\circ} \mathrm{C}$, during which time a mild evolution of gas was observed. 7 (2.2 $\mathrm{g}, 5.3 \mathrm{mmol})$ was then added as a solution in $10 \mathrm{~mL} \mathrm{DMSO}$, and the reaction allowed to stir overnight. After cooling, the reaction mixture was transferred to a separatory funnel, $100 \mathrm{~mL}$ EtOAc and $100 \mathrm{~mL} \mathrm{H}_{2} \mathrm{O}$ were added and the organic layer collected, washed once with a saturated aqueous $\mathrm{NaCl}$ solution, and dried over $\mathrm{MgSO}_{4}$. Solvent removal gave the crude product as a thick yellow oil which was chromatagraphed $\left(\mathrm{SiO}_{2}\right.$; EtOAc) to give the product as a white solid $(1.75 \mathrm{~g}, 64 \%$ yield $) .{ }^{1} \mathrm{H} \mathrm{NMR}\left(\mathrm{CDCl}_{3}\right.$, $200 \mathrm{MHz}) \mathrm{d}(\mathrm{ppm}) 8.93(\mathrm{bs}, 1 \mathrm{H}), 6.94(\mathrm{~s}, 1 \mathrm{H}), 4.41(\mathrm{~s}, 2 \mathrm{H}), 4.20(\mathrm{t}, 2 \mathrm{H}, J=6.4 \mathrm{~Hz}), 3.58$ (bs, 4H), $2.56(\mathrm{bm}, 2 \mathrm{H}), 1.93(\mathrm{~s}, 3 \mathrm{H}), 1.62(\mathrm{~m}, 4 \mathrm{H}), 1.25(\mathrm{bm}, 28 \mathrm{H}), 0.88(\mathrm{t}, 3 \mathrm{H}, J=6.4$ Hz). IR (thin film from $\mathrm{CH}_{2} \mathrm{Cl}_{2}$ on $\mathrm{NaCl}$ plate) $\square \max 3400,3140,2920,2825,1720$, 1680, 1450, 1190, $1010 \mathrm{~cm}^{-1}$. Anal. Calcd. for $\mathrm{C}_{28} \mathrm{H}_{50} \mathrm{~N}_{2} \mathrm{O}_{6}: \mathrm{C}, 65.86 ; \mathrm{H}, 9.87 ; \mathrm{N}, 5.48$. Found: C, 65.75; H, 10.37; N, 4.93.

Nanoparticle preparation. Amine protected $\square \mathrm{Fe}_{2} \mathrm{O}_{3}$ nanoparticles (MPN 4). In a 3neck $250 \mathrm{~mL}$ round bottom flask, trioctylamine $(20 \mathrm{~mL})$ is heated to $180^{\circ} \mathrm{C}$ and purged with Ar gas for 30 minutes. Iron cupferron (9) $(5 \mathrm{~mL}$ of a $0.3 \mathrm{M}$ solution in degassed octylamine) was then added over $\sim 5$ miuntes, during which time the reaction mixture became black with a brown precipitate. After stirring for 30 minutes at the elevated temperature, the reaction mixture was cooled to room temperature, and transferred to a $250 \mathrm{~mL}$ Erlenmeyer flask. $200 \mathrm{~mL}$ EtOH was then added, which fully precipitated the product as a brown solid. The product is stored like this until use, when it is filtered and washed extensively with EtOH. MPN 4: IR (thin film from $\mathrm{CHCl}_{3}$ on $\mathrm{NaCl}$ plate) $\square$ max 
2954, 2926, 2854, 2790, 1420, 1375, $570 \mathrm{~cm}^{-1}$. UV-Vis $\left(0.01 \mathrm{mg} / \mathrm{mL}\right.$ in $\left.\mathrm{CHCl}_{3}\right) 1_{\max }$ $250 \mathrm{~nm}$, shoulder to $580 \mathrm{~nm}$. TEM: average diameter size is $6.5 \pm 0.9 \mathrm{~nm}$.

Nanoparticle Place exchange. Synthesis of Thymine functionalized $\mathrm{G}-\mathrm{Fe}_{2} \mathrm{O}_{3}$ nanoparticles (MPN 3). In a $50 \mathrm{~mL}$ round bottom flask, MPN $4(400 \mathrm{mg})$ and $8(180 \mathrm{mg})$ were combined and dissolved in $30 \mathrm{~mL} \mathrm{CHCl}_{3}$, giving a dark red/brown solution. The reaction was heated to $50^{\circ} \mathrm{C}$ and stirred for 48 hours under argon. After cooling, the bulk of the $\mathrm{CHCl}_{3}$ was removed, and the product precipitated with $\mathrm{MeOH}$ to give a brown solid. Before use, this product was filtered and washed with $\sim 100 \mathrm{~mL} \mathrm{MeOH}$ to ensure removal of any nonattached ligand. IR (thin film from $\mathrm{CHCl}_{3}$ on $\mathrm{NaCl}$ plate) $\square \max 3380$, 2910, 2820, 1690, 1610, 1450, 1350, 1020, $590 \mathrm{~cm}^{-1}$. 

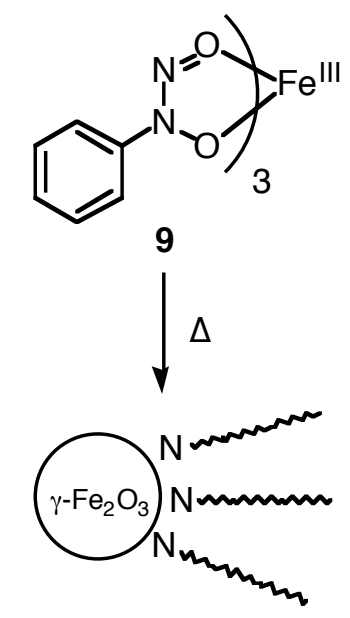

MPN 10

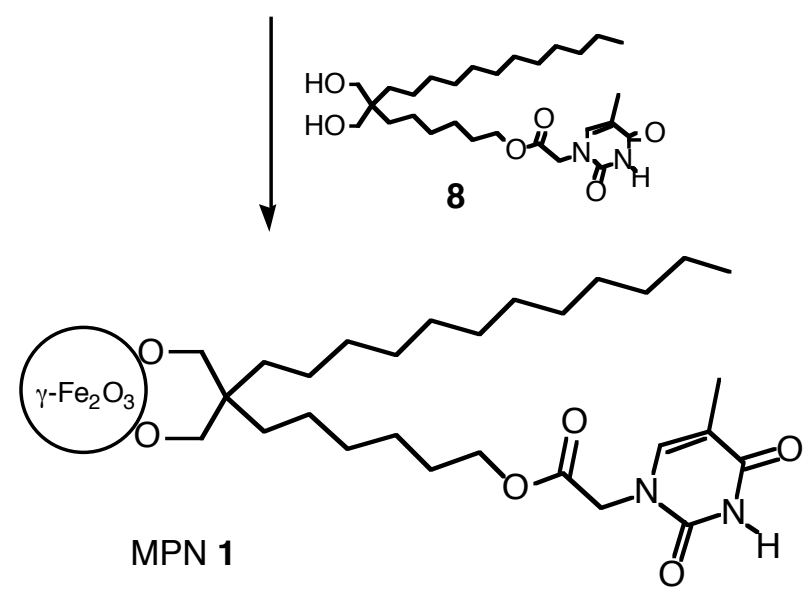

Scheme S3. Preparation of MPN 1. 


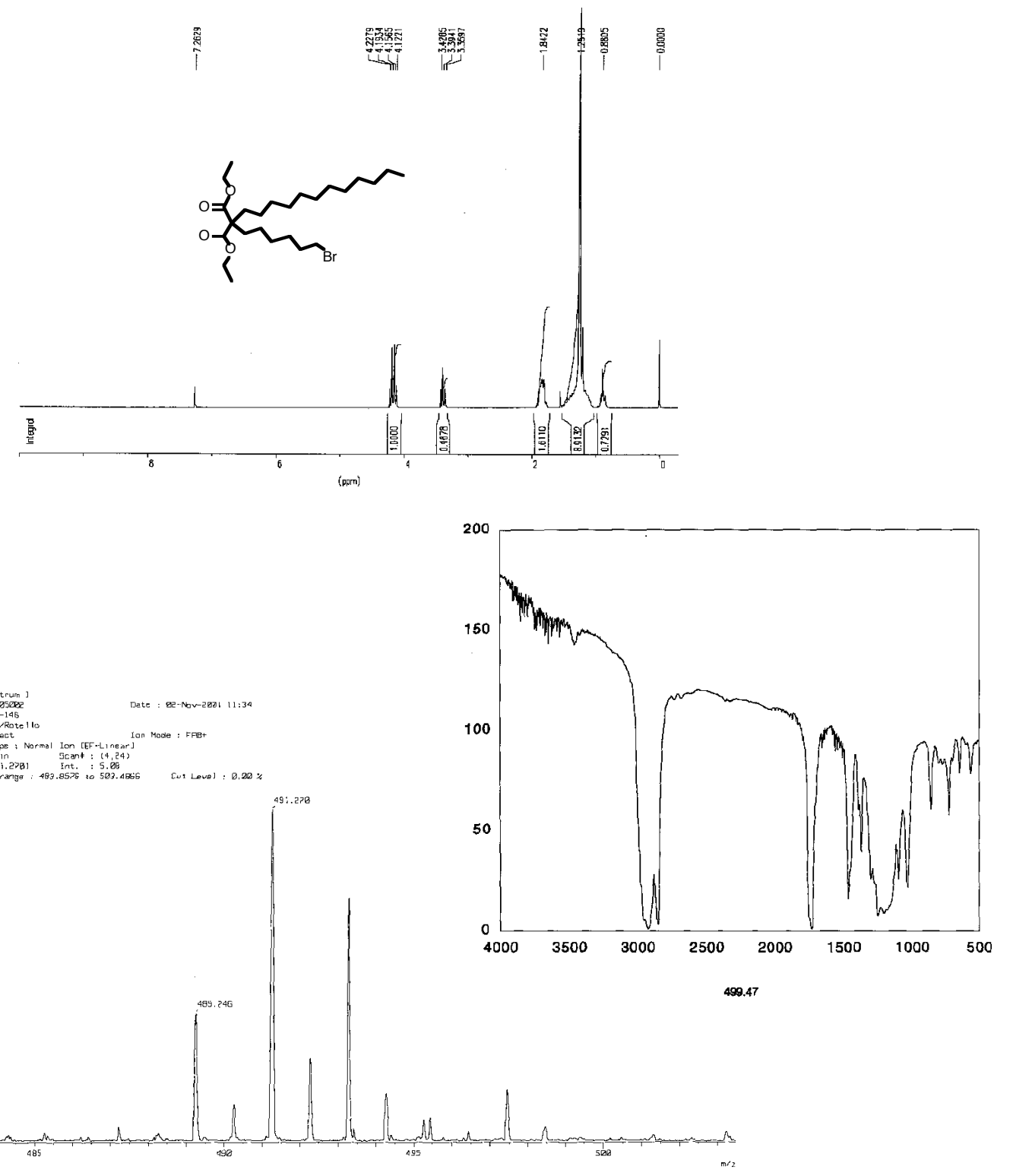

Figure S5. Spectral data for 6. 

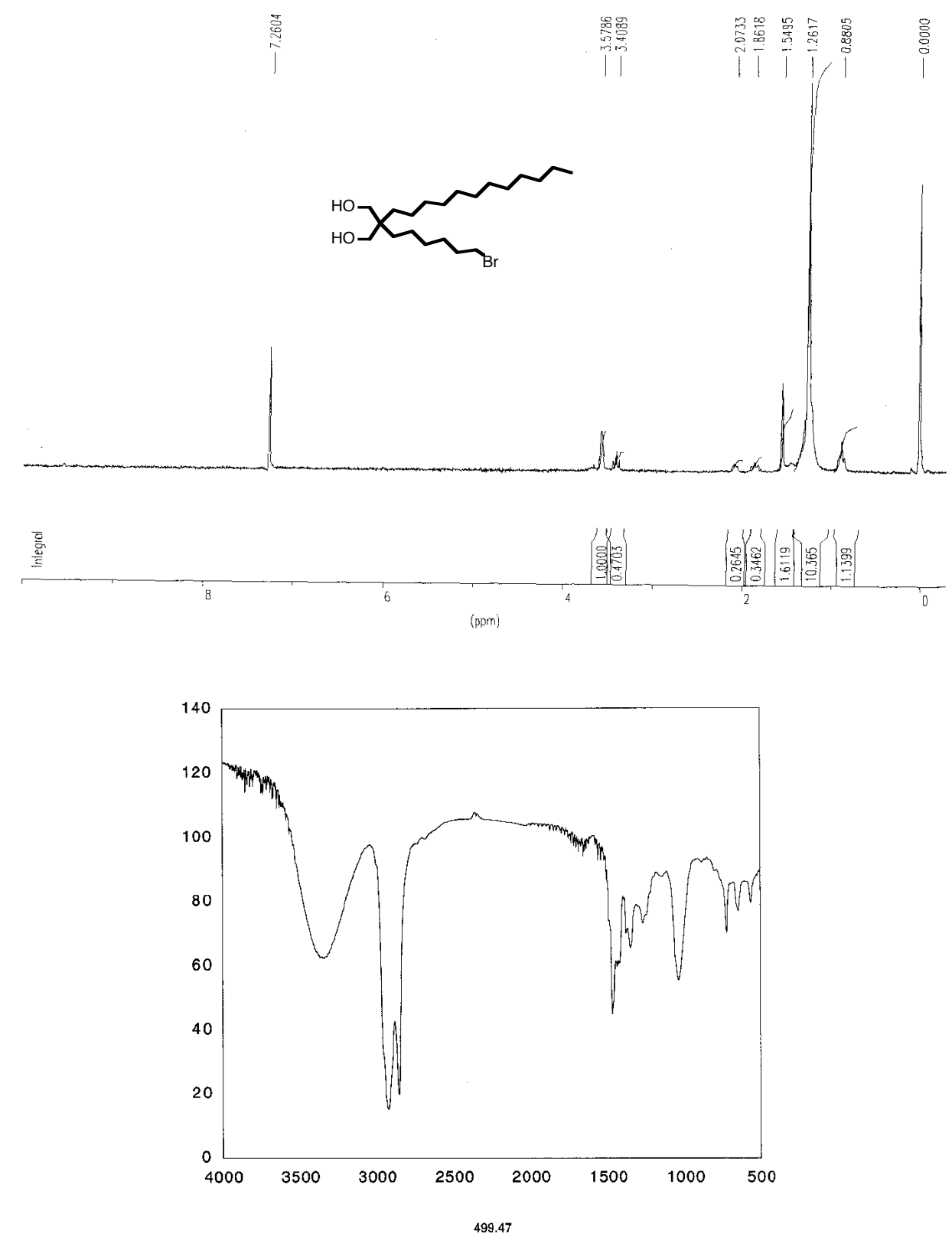

Figure S6. Spectral data for 7. 

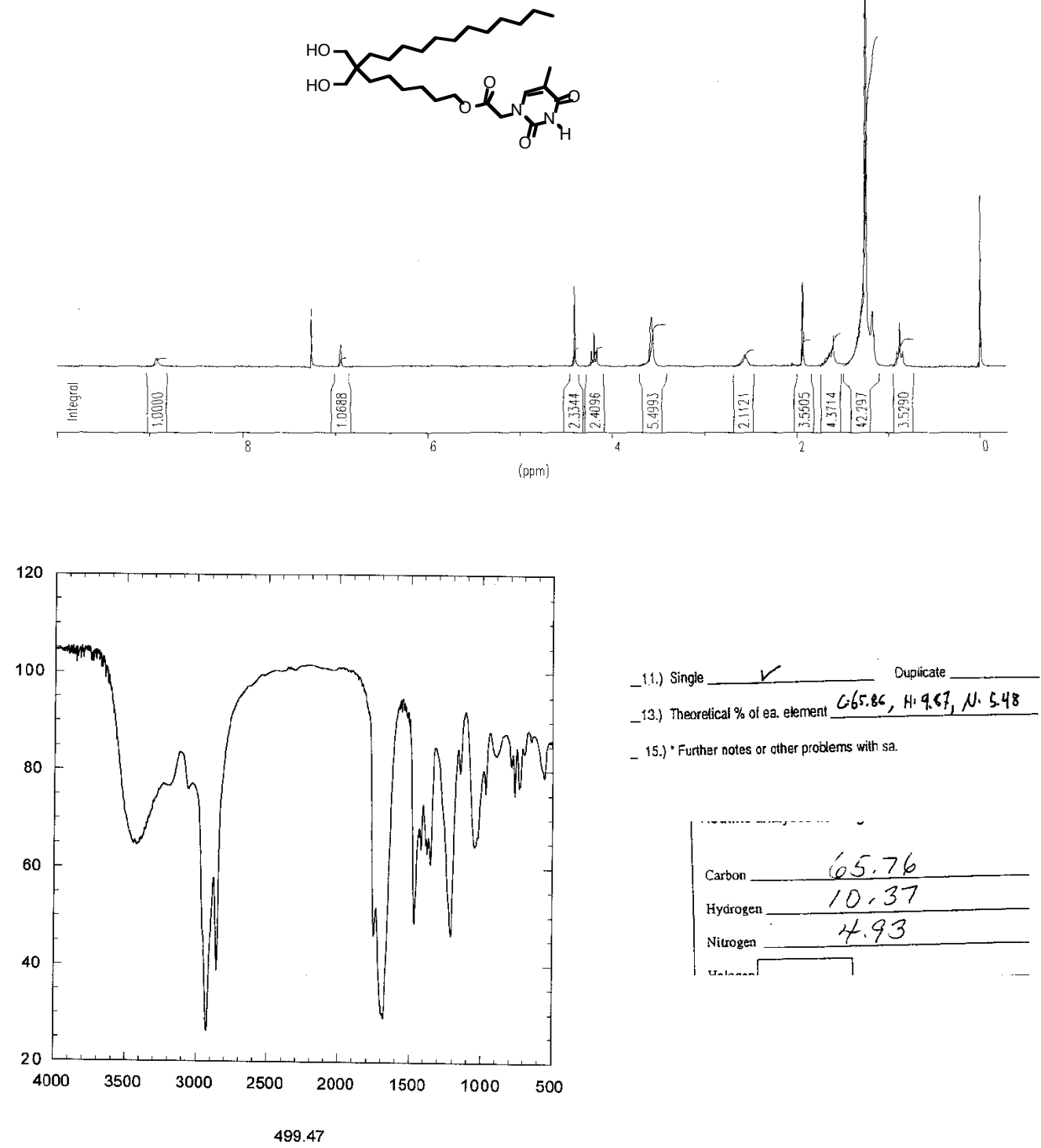

- 15.) Further notes or cther problems with sa.

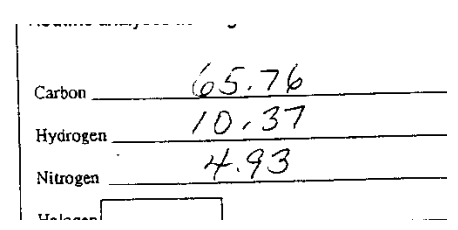

Figure S7. Spectral data for 8 . 

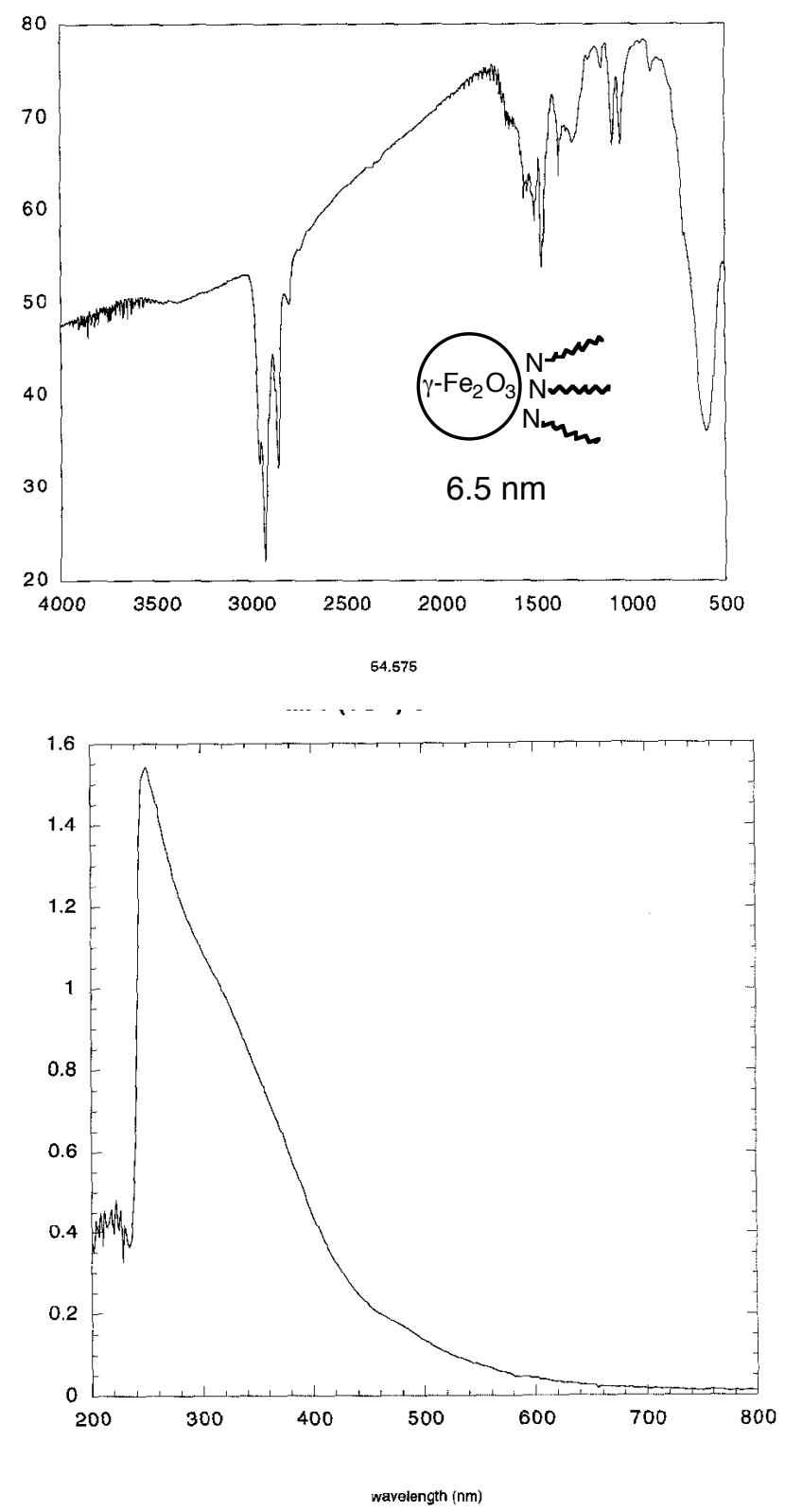

Figure S8. Spectral data for MPN 4. 


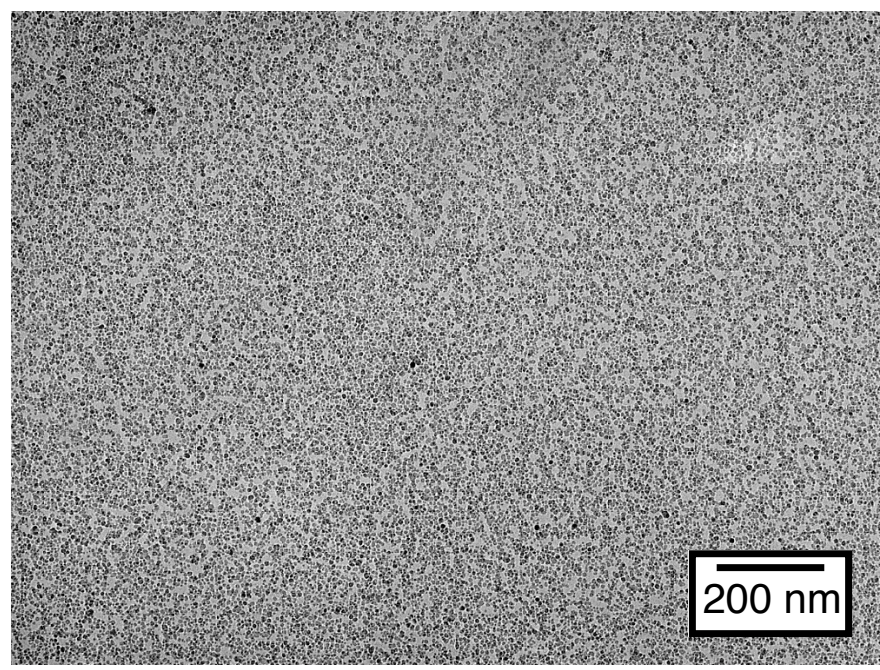

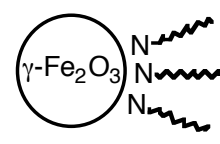

$6.5 \mathrm{~nm}$

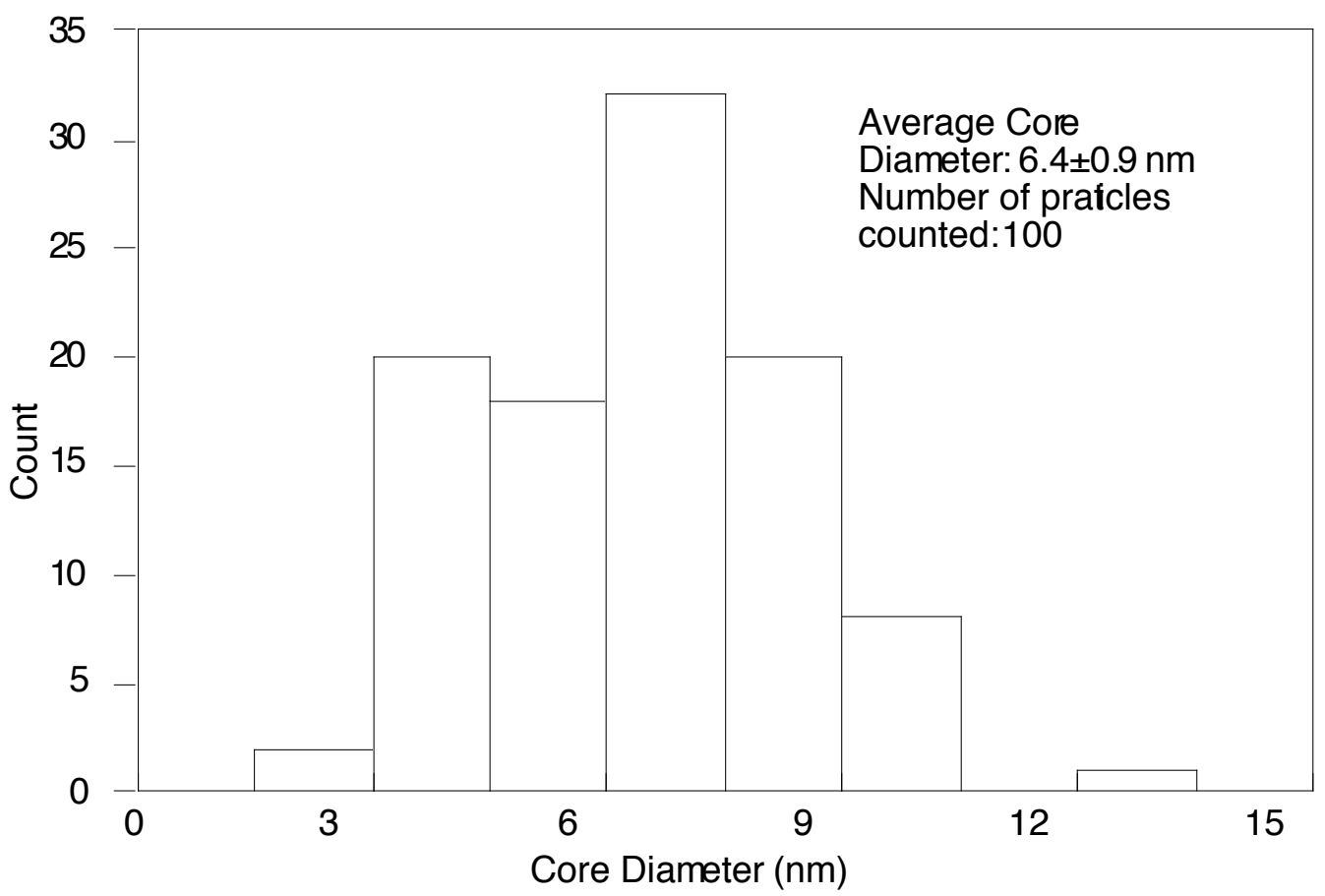

Figure S9. TEM and histogram of MPN 4. 

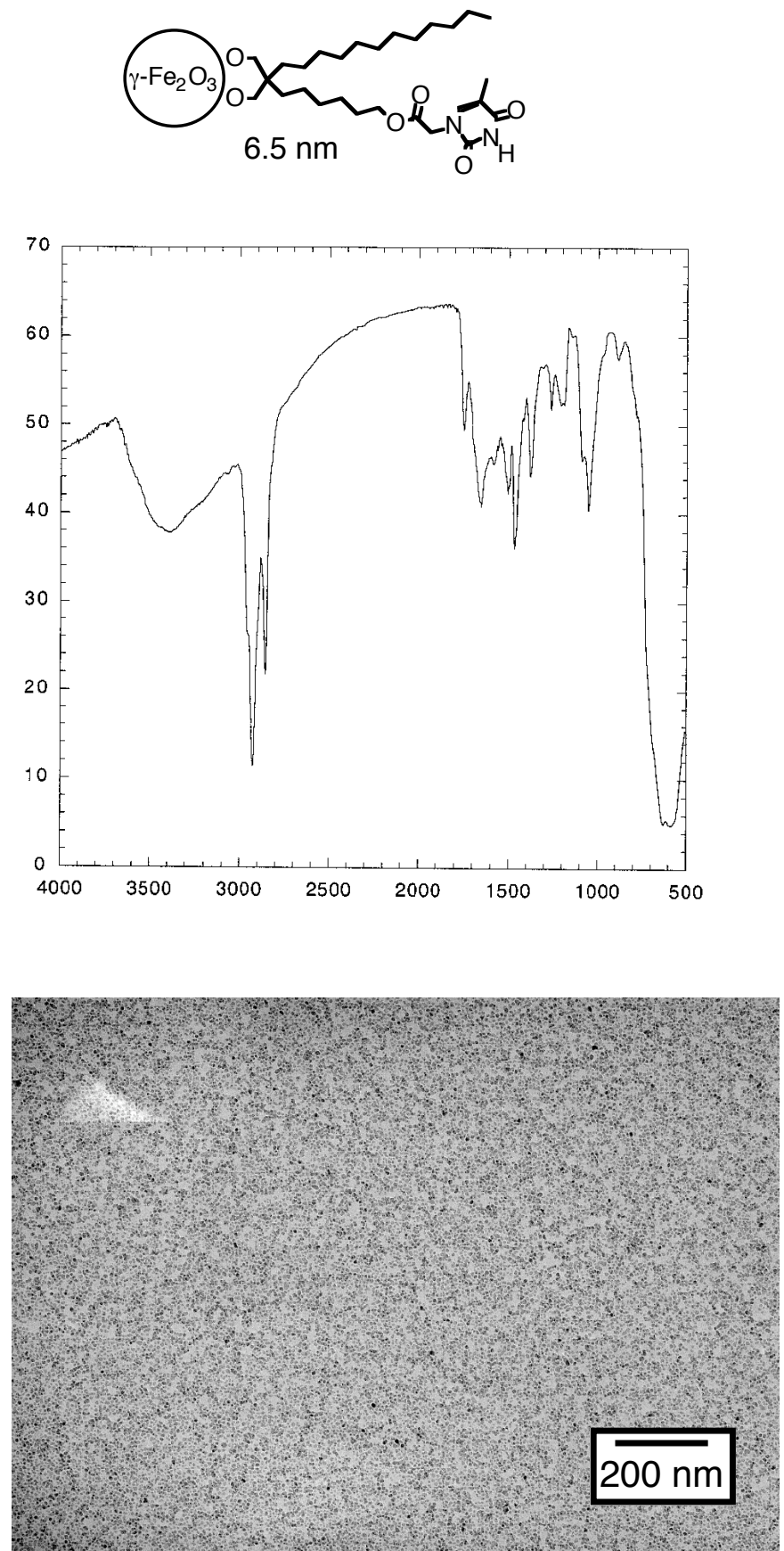

Figure S10. IR and TEM of MPN 3. 


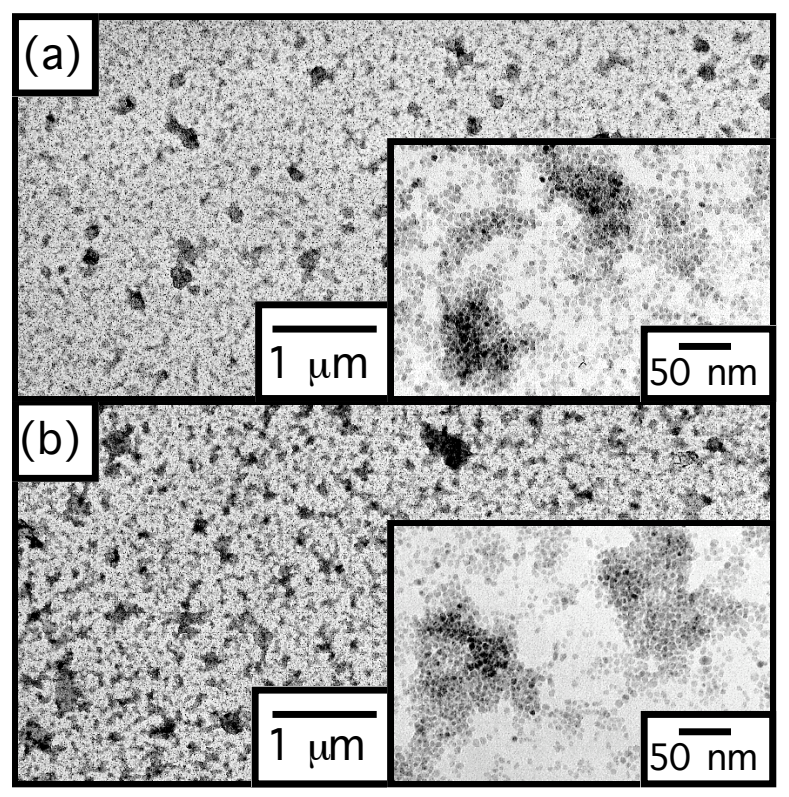

Figure S11. TEM images for MPN 1 (a) precipitated with hexanes and (b) assembled with polymer $\mathbf{1}$.

Table S1. Elemental Analysis and percent iron oxide content of MPN 1 aggregates. Samples are MPN 3 (1) precipitated with hexanes or assembled with (2) polymer 1, (3) polymer 2.

\begin{tabular}{ccccccc}
\hline Sample & $\mathrm{C}(\%)$ & $\mathrm{H}(\%)$ & $\mathrm{N}(\%)$ & $\mathrm{Fe}(\%)$ & $\begin{array}{c}\text { Sample Weight } \\
(\mathrm{mg})\end{array}$ & $\begin{array}{c}\text { Weight } \mathrm{Fe}_{2} \mathrm{O}_{3} \\
(\mathrm{mg})\end{array}$ \\
\hline 1 & 8.26 & 1.33 & 0.55 & 59.6 & 5.8 & 4.95 \\
2 & 25.10 & 3.02 & 4.74 & 47.0 & 3.2 & 2.15 \\
3 & 22.95 & 2.83 & 1.88 & 46.0 & 1.8 & 1.19 \\
\hline
\end{tabular}




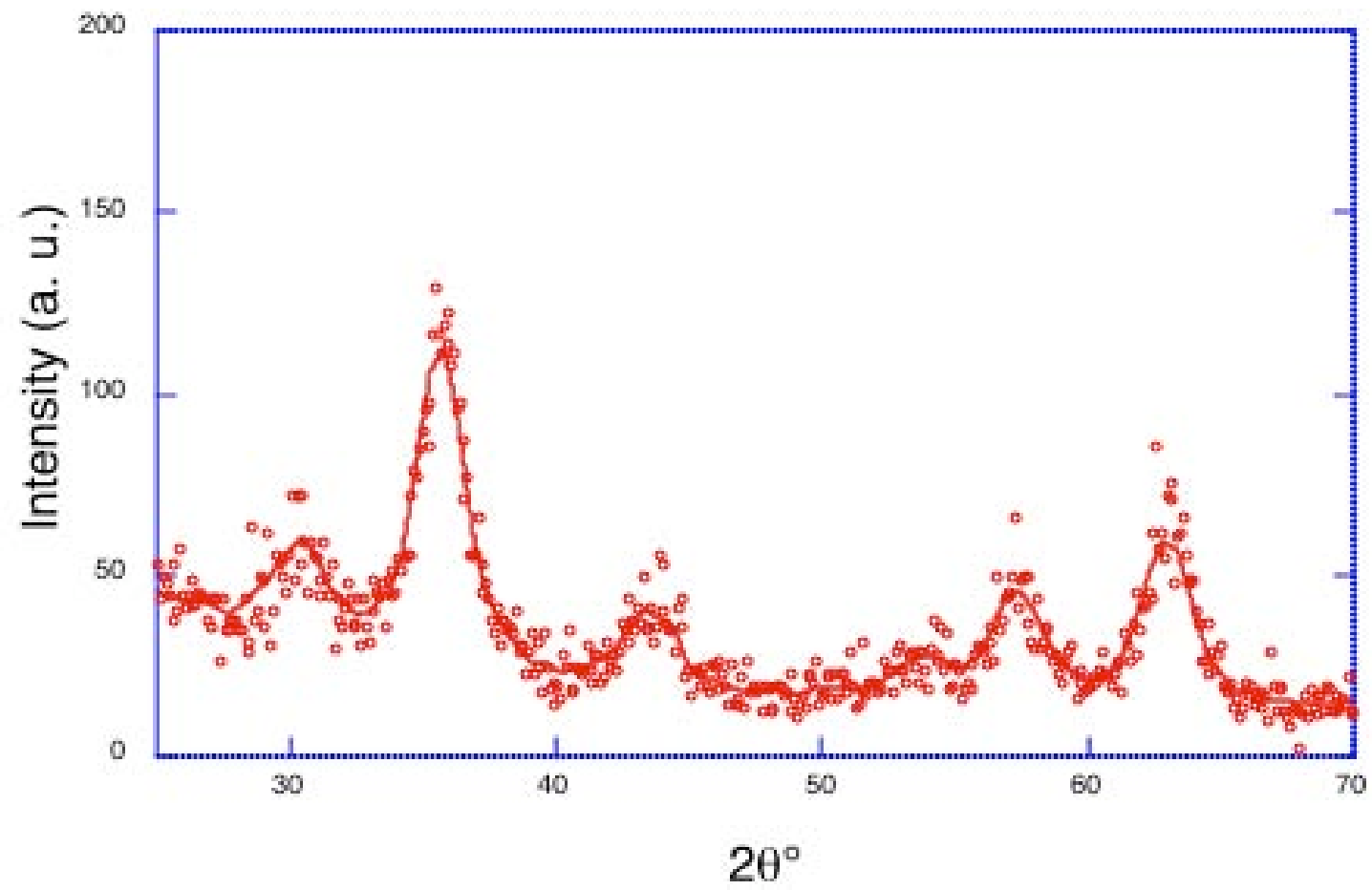

Figure S12. X-Ray Diffraction Pattern of MPN-1 assembled with polymer 2.

IR of the thin film samples used for SAXS and SQUID

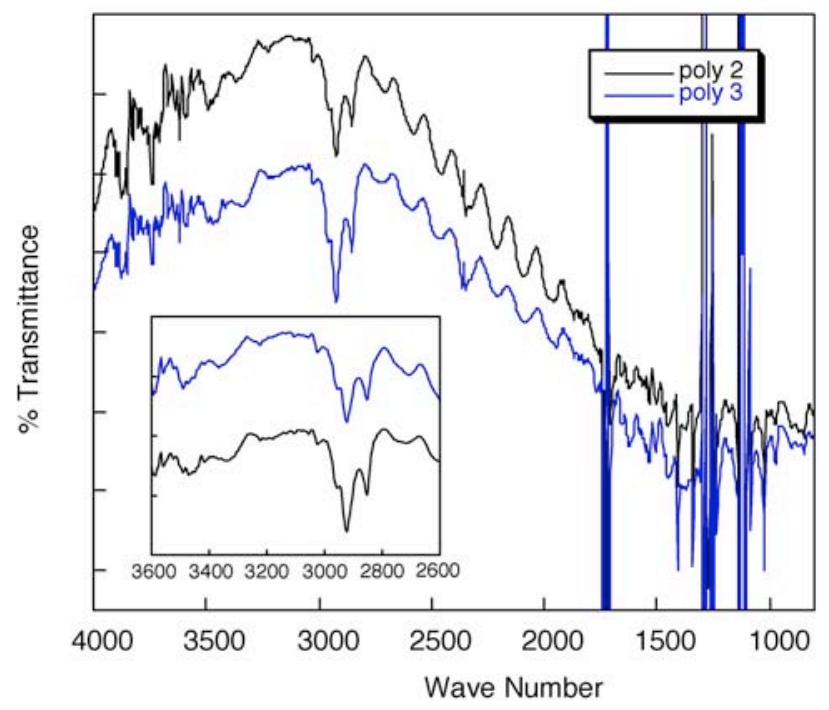

Figure S13. IR spectra of MPN 1 assembled with polymer 2 and $\mathbf{3}$. 


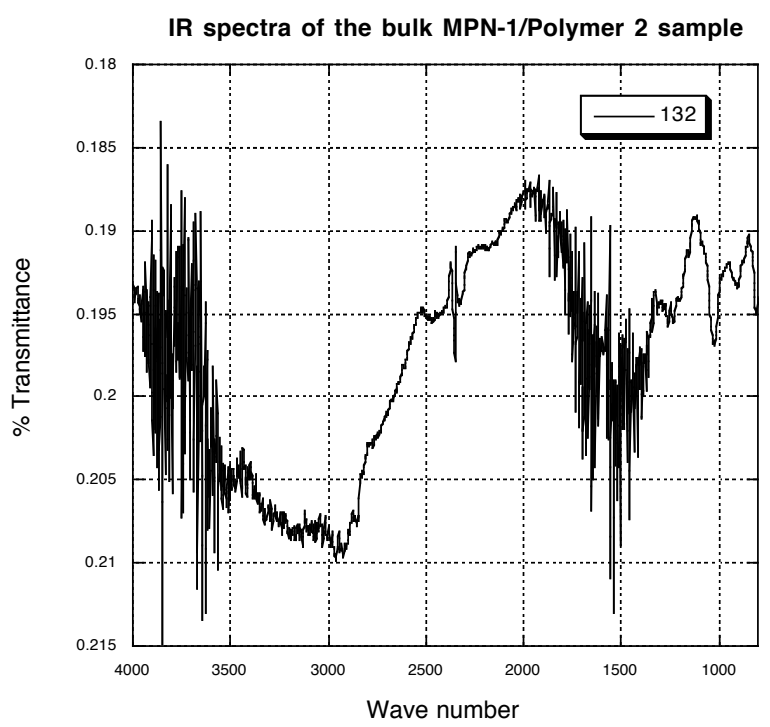

Figure S14. IR spectra of the bulk MPN-1/Polymer 2 assembly.

1) A signal at $\square-9.5$ ppm was observed, implying the presence of some aldehyde. This byproduct was typically about $5-10 \%$ of the product. Stirring the reaction for much longer than 15 minutes or warming leads to the rapid reduction of the alkyl bromide, and so a second $\mathrm{NaBH}_{4}$ reduction was used to complete the reaction. 